\title{
Microwave Assisted Synthesis of Xanthan gum- cl-Dimethyl acrylamide hydrogel based Silica hydrogel as Adsorbent for Cadmium (II) Removal
}

\author{
Edwin Makhado, Sadanand Pandey, Misook Kang and Elvis Fosso-Kankeu
}

\begin{abstract}
The present work highlights the synthesis of xanthan gum-cl-Dimethyl acrylamide hydrogel containing silica via microwave assisted method,in which N, N'-methylene bis-acrylamide (MBA) and ammonium persulfate (APS) were used as crosslinker and initiator, respectively. Silica was incorporated into the hydrogel matrix during the grafting reaction. The formation of XG-clDMAA/ $/ \mathrm{SiO}_{2}$ hydrogel nanocomposite under optimized reaction conditions was verified by the infrared spectra (FTIR) and Scanning electron microscopy (SEM). XG-cl-DMAA/SiO ${ }_{2}$ hydrogel nanocomposite was used for adsorption of $\mathrm{Cd}^{2+}$ ions from aqueous solution. The $\mathrm{Cd}^{2+}$ ions adsorption was measured by inductively coupled plasma mass spectrometry. The factors influencing adsorption capacity of the absorbents such contact time, and initial dye concentration were investigated via a batch adsorption system. The maximum adsorption capacity, $\mathrm{q}_{\max }$, of $150.7 \mathrm{mg} /$ gat $30^{\circ} \mathrm{C}$ was calculated based on the Langmuir isotherm. Heavy metal adsorption data fitted well to the pseudo-second-order model and equilibrium data were best described by Langmuir model.
\end{abstract}

Keywords - Xanthan gum; hydrogel nanocomposite; Microwave irradiation; Adsorption; Isotherm

\section{INTRODUCTION}

The steady growth of industrialization, results in the excessive releaseof various types of pollutants into water sources which is a major environmental problem. Toxic heavy metals such as $\mathrm{Cd}^{2+}, \mathrm{Cr}^{6+}, \mathrm{Pb}^{2+}, \mathrm{Hg}^{2+}, \mathrm{Cu}^{2+}$ and $\mathrm{As}^{3+}$ are continuously discharged from various industries like tanneries, metal plating, battery manufacturing, mining operations, printing and pigment and oil refining. Some of these metal ions are resistant of biological degradation and can accumulate in humans, threatens to cause serious diseases and disorders [1].

*Sadanand Pandey is with the Department of Chemistry, College of Natural Science, Yeungnam University, 280 Daehak-Ro, Gyeongsan, Gyeongbuk, 38541, Republic of Korea.

Misook Kang is with the Department of Chemistry, College of Natural Science, Yeungnam University, 280 Daehak-Ro, Gyeongsan, Gyeongbuk, 38541, Republic of Korea

Edwin Makhado is with the Department of Chemistry, School of Physical and Mineral Sciences, University of Limpopo, Polokwane, Sovenga 0727, South Africa

Elvis Fosso-Kankeu is with Water Pollution Monitoring and Remediation Initiatives Research Group, School of Chemical and Minerals Engineering, North-West University, Potchefstroom-South Africa.
Different researchers have employed various techniques for the removal of synthetic dyes and heavy metal ions from aqueous medium [2-4]. These methods include coagulationflocculation, reverse osmosis, membrane separation, electrochemical treatment, photocatalysis, solvent extraction, oxidation-reduction, and adsorption [2-5]. The adsorption is globally recognized as the most promising technique for the removal of heavy metals and dyes from the wastewater due to its efficiency and cost-effective nature [5-9].

In this concern, the use of low cost hydrogels with porous structure attract special attention and gaze at as a good candidate for water remediation due to their three-dimensional crosslinked structure that can swell in water and trap the solute materials. Biopolymers are playing a vital role in many application of nanotechnology [10-19]. Water purification is among the one out of many application. In addition, application of polymeric hydrogels as adsorbents for effective removal of toxic metal ions has been considered by various researchers because of characteristic properties such, high adsorption capacity, and chemical stability as well as ionic functional groups which can remove metal ions from wastewater. Other characteristic properties which make hydrogels to stand out among other adsorbent materials are the ability of the incorporation of various chelating groups into the polymeric networks, recovery capacities and regeneration for repeated recycles [20]

In recent years, hydrogels based on organic/inorganic $(\mathrm{O} / \mathrm{I})$ hydrogels nanocomposite have been employed as adsorbents to remove heavy metals and dyes from wastewater. Some research works have reported on developing hydrogels nanocomposite because of their enhanced mechanical/thermal stability and swelling properties when compared with the hydrogels without additives [21]. In this direction, inorganic components such carbon-based, montmorillonite, polymeric, ceramic, and metallic nanomaterials [22-24] are introduced in the hydrogel polymeric matrix for the engineering of hydrogels nanocomposite. Silica (SiO2) based nanocomposites have attracted great attention because they are easy availability, low-cost, and effortless surface modification $[25,26]$ Ghoraiet al., reported the nanocomposite based on nanosilica for removal of $\mathrm{Pd} 2+$ ions from aqueous solutions [27]. Pourjavadi et al., prepared chitosan-g-acrylic acid based modified nanosilica hydrogel nanocomposite for heavy metal ion removal [28].

Very recently, gum xanthan- and $\mathrm{SiO} 2$-based hybrid 
nanocomposites have been used as adsorbents for the removal of dyes and heavy metal ions from aqueous solutions. To the best of our knowledge, no similar work have been reported based on the adsorption performance of XG-clDMAA/SiO2hydrogel nanocomposite can be found in literature so far. The present work investigates the efficiency of the XG-cl-DMAA/SiO2hydrogel nanocomposite in the removal of $\mathrm{Cd} 2+$ ionsfrom aqueous solutions. The equilibrium removal efficiency was studied using isotherm models and kinetic parameters of the adsorption process.

\section{MAterials AND Method}

\section{A. Materials}

The biopolymer, xanthan gum (XG) from Xanthomonas campestris was supplied by Sigma-Aldrich (South Africa). Dimethyl acrylamide (DMAA, 99\%) monomer was obtained from Sigma-Aldrich (Netherlands) and acetone was procured from Merck (South Africa)and was used without further purification. Initiator ammonium persulfate (APS) ( $\geq 98 \%$; 248614), the cross linker N, N'-methylene bis-acrylamide (MBA), 99\%, cadmium nitrate tetrahydrate, 98\%, were obtained from Sigma-Aldrich (South Africa) and used without further purification. Sodium hydroxide $(\mathrm{NaOH})$ and Hydrochloric acid (HCL) were procured from Merck (South Africa). All reagents used were of analytical grade. For all the experiments, deionized (DI) water was used. The stock solution of $\mathrm{Cd}^{2+}$ ions $(1000 \mathrm{mg} / \mathrm{L})$ was prepared by dissolving an appropriate amount of cadmium nitrate tetrahydrate in $1 \mathrm{~L}$ of deionized water, and the stock solution was further diluted for batch experiments.

\section{B. Characterization}

Samsung (Model No. ME9114W1; 1500 W, Made: Malaysia) domestic microwave oven having $2450 \mathrm{MHz}$ microwave frequency and a power output from 0 to $1000 \mathrm{~W}$ was used for synthesis of hydrogel nanocomposite. The $\mathrm{pH}$ of the reaction mixture was adjusted using $\mathrm{HCl}$ or $\mathrm{NaOH}$ $(0.1 \mathrm{M})$. The $\mathrm{pH}$ measurements were made with HI 9811-5/HI 1285-5 (Romania). FTIR spectra were recorded on a Spectrum-100 Perkin Elmer, USA, in the spectral range of 4000 to $400 \mathrm{~cm}^{-1}$ with a resolution of 4 . The samples were compressed into pellets using spectroscopic grade $\mathrm{KBr}$ (Sigma-Aldrich, South Africa). The surface morphologies of the samples were examined by a scanning electron microscopy (SEM), (TESCAN, VEGA SEM) under a $20 \mathrm{kV}$ electron acceleration voltage. To avoid charging these samples were coated with carbon.

\section{Preparation of Silica oligomer}

Tetraethoxysilane $(2.5 \mathrm{~mL})$ was dissolved in ethanol $(2.5$ $\mathrm{mL}$ ). In a second solution $1.75 \mathrm{~mL}$ of $12 \mathrm{~N}$ ammonium hydroxide was prepared independently. All the two solutions were emptied together into a reaction glass flask with $20 \mathrm{~mL}$ of deionized water and kept under tender blending for more than $18 \mathrm{hrs}$ at room temperature to develop monodisperse $\mathrm{SiO}_{2}$ particles inside the medium. The following blend was then be dissipated in air at $40{ }^{\circ} \mathrm{C}(4 \mathrm{~h}), 60{ }^{\circ} \mathrm{C}(5 \mathrm{~h}), 70{ }^{\circ} \mathrm{C}(3 \mathrm{~h})$ and $80{ }^{\circ} \mathrm{C}$ for $1 \mathrm{~h}$ until a dry material, $\mathrm{SiO}_{2}$ was acquired.

\section{Synthesis of XG-cl-DMAA/SiO ${ }_{2}$ hydrogel nanocomposite}

A polymer matrix composed of XG-cl-DMAA was prepared by using MBA as crosslinker and APS as initiator in a domestic microwave. The grafting of DMAA onto XG in the presence of MBA cross linker by free radical copolymerization technique. XG (0.1 g) was dissolved was homogenously dissolve in a $100 \mathrm{~mL}$ open beaker containing DI. Calculated amount of AA, MBA were added and APS was added in order to initiate the reaction of graft copolymerization. Then $0.1 \mathrm{~g}$ of $\mathrm{SiO}_{2}$ was dispersed in $5 \mathrm{~mL}$ of DI water, and then sonicated for $5 \mathrm{~min}$ by using ultrasonicator, the $\mathrm{SiO}_{2}$ solution was added to the graft copolymerization reaction in a $100 \mathrm{~mL}$ open beaker. The beaker was exposed under fixed microwave power for a definite time period in a domestic microwave oven with a microwave frequency of $2450 \mathrm{MHz}$. After desired time period, the XG-cl-DMAA/SiO ${ }_{2}$ hydrogel nanocomposite was precipitated by pouring the reaction mixture into a large quantity of acetone and washed well to remove adhered homopolymer, if any is present along with graft copolymers. The precipitated copolymer was filtered and the copolymer samples obtained were finally dried under vacuum at $60{ }^{\circ} \mathrm{C}$ for $>24$.

\section{E. Adsorption studies}

$\mathrm{Cd}^{2+}$ sorption investigations were performed by the batch method. Adsorption examinations were carried out usingXGcl-DMAA/ $\mathrm{SiO}_{2}$ hydrogel nanocomposite as adsorbent on a temperature controlled incubator shaker set at $130 \mathrm{rpm}$ kept up at $30{ }^{\circ} \mathrm{C}$ for $120 \mathrm{~min}$. Here, known measures of adsorbents $(25 \mathrm{mg})$ were completely mixed with $20 \mathrm{~mL}$ of individual $\mathrm{Cd}^{2+}$ solutions, whose concentrations and $\mathrm{pHs}$ (5.0) were beforehand known. After the PE plastic bottles were shaken for the desired time, the suspensions were filtered through $0.45 \mu \mathrm{m}$ PVDF syringe filters. The concentration of the unadsorbed $\mathrm{Cd}^{2+}$ ions left behind in each solution was analyzed using an inductively coupled plasma mass spectrometry. The equilibrium uptake was calculated using Equation (1)

$$
\mathrm{qe}=(C o-C e) \times \frac{V}{W}
$$

where, qe is the equilibrium capacity of $\mathrm{Cd}^{2+}$ ions on the adsorbent $(\mathrm{mg} / \mathrm{g})$, Co denotes the initial and the Ce denotes the equilibrium concentrations $(\mathrm{mg} / \mathrm{L})$ of $\mathrm{Cd}^{2+}$ ions, respectively. $\mathrm{V}$ is the volume of dye solution used (L) and $\mathrm{W}$ is the weight of adsorbent (g) used. All the batch experiments were carried out in triplicate and results represented here are the average of three readings.

\section{RESUlTS AND DISCUSSION}

\section{A. FTIR-spectroscopy}

The structural changes of $\mathrm{XG}$ and XG-clDMAA/ $\mathrm{SiO}_{2}$ hydrogel nanocomposite were confirmed by FTIR spectroscopy and the results are presented Fig. 1(a). Pure XG had the characteristic bands at $3246 \mathrm{~cm}^{-1}, 2932 \mathrm{~cm}^{-1}$, and $1404 \mathrm{~cm}^{-1}$ due to the characteristic stretching vibration of both primary and secondary $\mathrm{O}-\mathrm{H}$ bonds , $-\mathrm{CH}$ stretching of 
alkyl group, and at $1404 \mathrm{~cm}^{-1}$ due to $\mathrm{CH}$ bending of methyl group, respectively. Additional characteristic absorption bands of the polysaccharide appear at $1023 \mathrm{~cm}^{-1}$ due to stretching of the $\mathrm{C} \mathrm{O}$ bond [6].In the cases of XG-cl-DMAA/ $\mathrm{SiO}_{2}$ hydrogel nanocomposite, a hump at $3142 \mathrm{~cm}^{-1}$ appeared in a broad absorption peak of XG after the surface-modification with DMAA/ $/ \mathrm{SiO}_{2}$. The band at $1643 \mathrm{~cm}^{-1}$ can be attributed to carbonyl of acrylamide. Furthermore, characteristic band at $1036 \mathrm{~cm}^{-1}$ is due to the stretching vibration of $\mathrm{N}^{-\mathrm{CH}_{3}}$ [29]. These results indicated that DMAA was chemically grafted onto the XG.

\section{B. Electron microscopy characterization}

The surface morphologies of the XG and XG-clDMAA/ $/ \mathrm{SiO}_{2}$ are depicted in Fig. 1(b-c). SEM micrograph of the XG is shown in Fig. 1(b) and the granular morphology can be clearly seen which suggests the amorphous nature of the biopolymer [30-32]. The SEM of XG-cl-DMAA/ $\mathrm{SiO}_{2}$ displays rough irregular surface morphology shown in Fig. 1(b). The rough uneven surface morphology observed for XG-clDMAA/ $/ \mathrm{SiO}_{2}$ seems to have been covered by $\mathrm{Cd}^{2+}$ after the adsorption study. XG-cl-DMAA/ $\mathrm{SiO}_{2}$ after adsorption had smooth homogeneous surface morphology which evidenced $\mathrm{Cd}^{2+}$ loading onto the of XG-cl-DMAA/SiO $\mathrm{S}_{2}$ hydrogel nanocomposite (Fig. 1d).
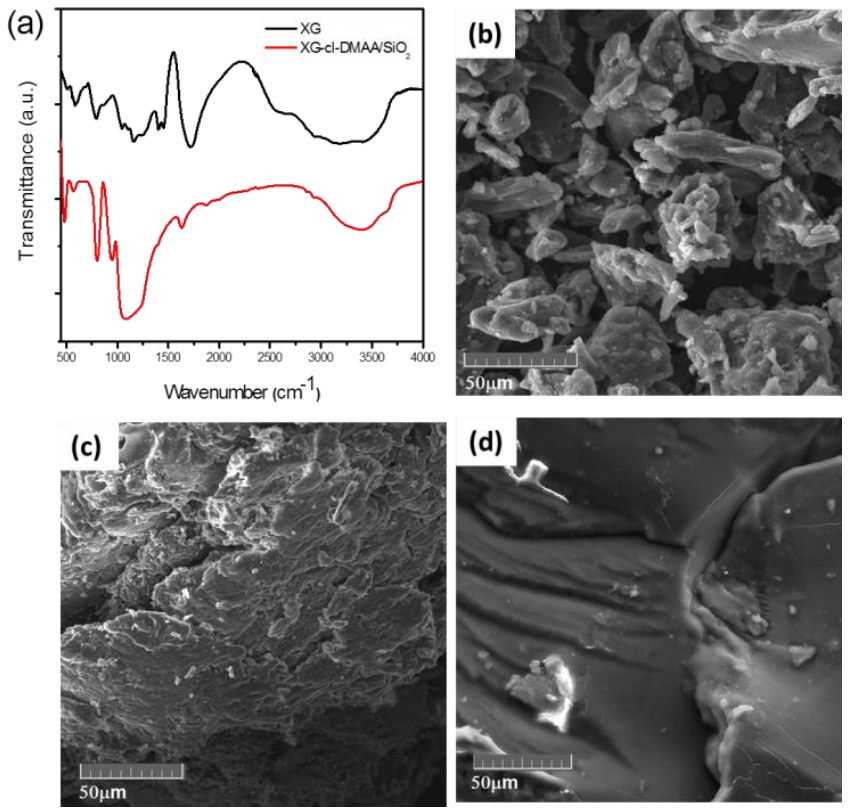

Fig. 1. Shows the (a) FT-IR spectra of the XG and XG-cl-

DMAA/ $/ \mathrm{SiO}_{2}$, SEM image resolution at 600x of (b) XG; (c) XG-clDMAA/SiO ${ }_{2}$ and (d) $\mathrm{Cd}^{2+}$ loaded XG-cl-DMAA/SiO ${ }_{2}$.

\section{Pseudo-first-order and the pseudo-second order} equations

$\mathrm{Cd}^{2+}$ removal by XG-cl-DMAA/SiO 2 hydrogel nanocomposite as a function of contact time was measured and the results are shown in Fig. 2.The kinetic parameters obtained at $100 \mathrm{mg} / \mathrm{L}$ concentration of $\mathrm{Cd}^{2+}$ areillustrated in Table 1. The Pseudo-first-order kinetic model of Langergren Equation (2) [33] and the Pseudo-second order kinetic Equation (3) [34] models are often used to govern the rate constant and to examine the mechanism of the adsorption process. Their linear forms can be expressed as:

$$
\begin{array}{r}
\frac{\log \left(q_{e}-q_{t}\right)}{q_{e}}=\log q_{e}-\frac{k_{1}}{2.030} \\
\frac{t}{q_{t}}=\frac{1}{k^{\prime} q_{e}^{2}}+\frac{t}{q_{e}}
\end{array}
$$

Where, qe $(\mathrm{mg} / \mathrm{g})$ is the adsorption capacity of XGcl-DMAA/ $\mathrm{SiO}_{2}$ hydrogel nanocomposite in equilibrium; $\mathrm{K}_{1}$ $\left(\mathrm{min}^{-1}\right)$ is the rate constant of the Pseudo-first-order model; and $\mathrm{K}_{2}\left(\mathrm{~g} \mathrm{mg}^{-1} \mathrm{~min}^{-1}\right)$ is the rate constant of the pseudosecond-order model. The experimental data in were fitted linearly by using Equation (2) and (3). These results indicated that the experimental data was in agreement with Pseudosecond-order kinetic model $\left(\mathrm{R}^{2}=0.997\right)$ for the adsorption of $\mathrm{Cd}^{2+}$ on XG-cl-DMAA/ $\mathrm{SiO}_{2}$ hydrogel nanocomposite compared to the Pseudo-first-order model $\left(\mathrm{R}^{2}=0.669\right)$. Furthermore, these results indicated that the adsorption of $\mathrm{Cd}^{2+}$ on XG-cl-DMAA/SiO ${ }_{2}$ hydrogel nanocomposite was mainly a chemical process.
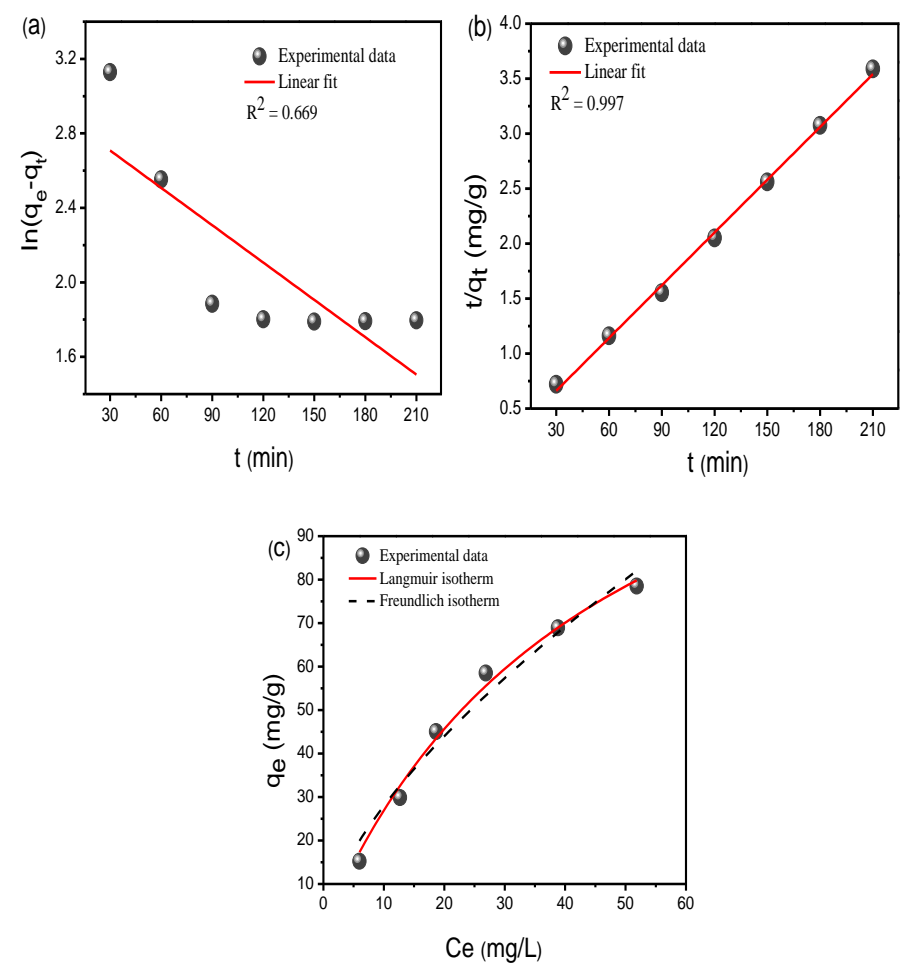

Fig. 2. Adsorption kinetics of $\mathrm{Cd}^{2+}$ onto according to (a) Pseudo-firstorder model, (b) pseudo-second-order model, and (c) non-linear Langmuir and Freundlich isotherm model.

TABLE I KINETIC PARAMETERS FOR $\mathrm{CD}^{2+}$ ADSORPTION BY XG-CL-

\begin{tabular}{|c|c|}
\hline Pseudo-first-order & Pseudo-second-order \\
\hline $\begin{array}{lll}\mathrm{qe}(\mathrm{mg} / \mathrm{g}) & \mathrm{k}_{1}\left(\mathrm{~min}^{-1}\right) & \mathrm{R}^{2}\end{array}$ & $\mathrm{qe}(\mathrm{mg} / \mathrm{g}) \mathrm{k}_{2}(\mathrm{~g}(\mathrm{mg} / \mathrm{min})) \mathrm{R}^{2}$ \\
\hline 0.669 & 1.8935 \\
\hline
\end{tabular}

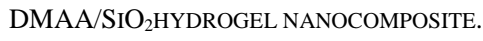




\section{Langmuir isotherm}

Adsorption isotherm studies are remarkably significant to determine the efficacy of adsorption. Several adsorption isotherms initially used for gas phase adsorption are available and readily adopted to correlate adsorption equilibria in heavy metals adsorption. In this work, the adsorption isotherms were investigated using two equilibrium models, which are Langmuir and Freundlich isotherm models.

The Langmuir isotherm is based on the assumption that monolayer adsorption takes place on an adsorbent that have a structurally homogeneous surface, on which the binding sites have the same affinity for the adsorption, and no interaction occurs between adsorbates [35]. The equation representing nonlinear Langmuir isotherm model is given as:

$$
q e=\frac{q_{\max } K_{L} C_{e}}{1+K_{L} C_{e}}
$$

where, qe is adsorption capacity at equilibrium $(\mathrm{mg} / \mathrm{g}), \mathrm{Ce}$ is equilibrium concentrations of adsorbate in liquid phases (mg/L), qmax is the maximum adsorption capacity of the adsorbent $\left(\mathrm{mg} / \mathrm{g}\right.$ ) and $\mathrm{K}_{\mathrm{L}}$ is the Langmuir adsorption constant related to the energy of adsorption (L/mg). Langmuir constants, $\mathrm{K}_{\mathrm{L}}$ and $\mathrm{q}_{\max }$, can be obtained from the non-linear fit of qe versus $\mathrm{Ce}$.

\section{E. Freundlich isotherm}

The Freundlich isotherm is based on the assumption that the adsorption process takes place on heterogeneous surfaces, and adsorption capacity is related to the concentration of dye at equilibrium [36]. The nonlinear Freundlich isotherm is expressed as:

$$
\mathrm{qe}=\mathrm{K}_{\mathrm{F}} \mathrm{Ce}^{\frac{1}{n}}
$$

Where, $\mathrm{K}_{\mathrm{F}}$ and $\mathrm{n}$ are the Freundlich constants related to adsorption capacity and indicative of the energy or intensity of the reaction, respectively, qe and $\mathrm{Ce}$ are the adsorption capacity at equilibrium (mg/g) and equilibrium concentrations of adsorbate in liquid phases $(\mathrm{mg} / \mathrm{L})$, respectively. The Freundlich constants, $\mathrm{K}_{\mathrm{F}}$ and $\mathrm{n}$, can be obtained from the nonlinear fit of qe versus Ce.

It is seen from Table 2 that the correlation coefficient of Langmuir isotherm $\left(\mathrm{R}^{2}=0.989\right)$ models is more than that of Freundlich isotherm model $\left(\mathrm{R}^{2}=0.966\right)$. The adsorption isotherms of $\mathrm{Cd}^{2+}$ on $\mathrm{XG}-\mathrm{cl}-\mathrm{DMAA} / \mathrm{SiO}_{2}$ hydrogel nanocomposite indicated that Langmuir model more precise in evaluating the sorption equilibrium (see Fig. 2(c)). Langmuir model assumes that adsorption is monolayer coverage and the adsorption site on adsorbent surface is homogeneous [37-]. The maximum adsorption capacity $\mathrm{Cd}^{2+}$ on $\mathrm{XG}-\mathrm{cl}-$ DMAA/ $/ \mathrm{SiO}_{2}$ hydrogel nanocomposite was found to be 150.7 $\mathrm{mg} / \mathrm{g}$.

TABLE II ADSORPTION ISOTHERM STUDY OF $\mathrm{CD}^{2+}$ ADSORPTION BY XG-CLDMAA/SIO ${ }_{2}$ HYDROGEL NANOCOMPOSITE ACCORDING TO EQUILIBRIUM MODELS.

\begin{tabular}{lcc|lcc}
\hline \multicolumn{2}{l}{ Langmuir isotherm } & & \multicolumn{4}{l}{ Freundlich isotherm } \\
\hline qmax (mg/g) & $\mathrm{K}_{\mathrm{L}}$ & $\mathrm{R}^{2}$ & $\mathrm{n}$ & $\mathrm{K}_{\mathrm{F}}$ & $\mathrm{R}^{2}$ \\
\hline 150.7 & 0.027 & 0.989 & 1.527 & 6.185 & 0.966 \\
\hline
\end{tabular}

\section{CONCLUSION}

In this study, $\mathrm{XG}$-cl-DMAA/SiO ${ }_{2}$ hydrogel nanocomposite was successfully synthesized by microwave irradiation method. A new type of XG-cl-DMAA/SiO ${ }_{2}$ hydrogel nanocomposite sorbent was developed for the removal of $\mathrm{Cd}^{2+}$ from the aqueous medium. Cadmium removal was investigated via a batch adsorption system. The adsorption process was reached at equilibrium state within $120 \mathrm{~min}$ at $\mathrm{pH}$ 5.The adsorption followed pseudo-second-order kinetic and Langmuir isotherm models. The maximum adsorption capacity $\mathrm{Cd}^{2+}$ on $\mathrm{XG}$-cl-DMAA/ $\mathrm{SiO}_{2}$ hydrogel nanocomposite was $150.7 \mathrm{mg} / \mathrm{g}$ at $30^{\circ} \mathrm{C}$.

\section{CONFLICT OF INTEREST}

The authors declare no competing financial interest.

\section{ACKNOWLEDGEMENTS}

This study was supported by the National Research Foundation of Korea (NRF) grant funded by the Korea government (MSIT) (No. 2018R1A2B6004746). This work was also supported by Yeungnam University and The Faculty of Engineering, North West University.

\section{REFERENCES}

[1]. Malik, R. Ramteke, D. S. Wate, S. R. Adsorption of malachite green on ground nut shell waste based powdered activated carbon. Waste Management. 2007, 27, 1129-1138. https://doi.org/10.1016/j.wasman.2006.06.009

[2]. Pandit, P. Basu, S. Removal of ionic dyes from water by solvent extraction using reverse micelles. Environmental Science Technology. 2004, 38,2435-2442. https://doi.org/10.1021/es030573m

[3].Nataraj S.K, Hosamani, K.M, Aminabhavi T.M. Nanofiltration and reverse osmosis thin film composite membrane module for the removal of dye and salts from the simulated mixtures. Desalination. 2009, 249, 12-17. https://doi.org/10.1016/j.desal.2009.06.008

[4]. Q. Yuan, Q. Chen, L. Xiong, M. He, J. Luo, S.L. Au, C.T. Yin, S.F. $\mathrm{Cu} 2 \mathrm{O} / \mathrm{BiVO} 4$ heterostructures: synthesis and application in simultaneous photocatalytic oxidation of organic dyes and reduction of $\mathrm{Cr}(\mathrm{VI})$ under visible light. Chemical Engineering Journal, 2014, 255, 394-402. https://doi.org/10.1016/j.cej.2014.06.031

[5].Pandey S, A comprehensive review on recent developments in bentonite based materials used as adsorbents for wastewater treatment. Journal of Molecular Liquids 2017, 241, 1091-1113. https://doi.org/10.1016/j.molliq.2017.06.115

[6]. Makhado, E. Pandey, S. Nomngongo, P. Ramontja, J, Fast microwaveassisted green synthesis of xanthan gum grafted acrylic acid for enhanced methylene blue dye removal from aqueous solution. Carbohydrate Polymers, 2017, 176,315-326. https://doi.org/10.1016/j.carbpol.2017.08.093

[7]. Pandey, S, Ramontja J, Natural Bentonite Clay and Its Composites for Dye Removal: Current State and Future Potential. American Journal of Chemistry and Applications. 2016, 3, 8-19.

[8]. Pandey S, Ramontja J, Recent Modifications of bentonite Clay for Adsorption.\| Applications. Focus on science. 2016, 2, 1-10 https://doi.org/10.21859/focsci-020455

[9]Pandey S, Kang, M, 1P-685: Fast microwave-assisted green synthesis of locust bean gum grafted diethylamino ethyl methacrylate: An efficient metal ion removal, The Korean Society of Industrial and Engineering Chemistry, 2019, 274.

[10]. Pandey S, Ramontja J. Guar gum grafted poly (acrylonitrile) templated silica xerogel: Nanoengineered material for lead ion removal. J Anal Sci Technol. 2016, 7, 24. DOI 10.1186/s40543-016-0103-8. https://doi.org/10.1186/s40543-016-0103-8 
[11]. Pandey S, Nanda K. Au Nanocomposite Based Chemiresistive Ammonia Sensor for Health Monitoring. ACS Sensors.2015;1(1):55-62. https://doi.org/10.1021/acssensors.5b00013

[12]. Pandey S, Mishra S. Chromatographic resolution of racemic $\alpha$-amino acids: Chiral stationary phase derived from modified xanthan gum. Carbohyd Polym. 2013;92(2):2201-5. https://doi.org/10.1016/j.carbpol.2012.11.102

[13]. Pandey S. Highly Sensitive and Selective Chemiresistor Gas/Vapor Sensors based on Polyaniline Nanocomposite: A comprehensive review. J Sci Adv Mate Devic. 2016,1, 431-453. https://doi.org/10.1016/j.jsamd.2016.10.005

[14]. Pandey S, Nanda K. One-dimensional Nanostructure Based Chemiresistor Sensor. Nanotechnology. 2013; 10:1-17.

[15]. Pandey S, Mishra S. Bioceramics: Silica- Based Organic- Inorganic Hybrid Materials for Medical Applications. Nanomedicine for Drug Delivery and Therapeutics: John Wiley \& Sons, Inc.; 2013. p. 135-61. https://doi.org/10.1002/9781118636299.ch5

[16].Pandey S, Mishra S. Chemical Nanosensors for Monitoring Environmental Pollution. Application of Nanotechnology in Water Research: John Wiley \& Sons, Inc.; 2014. p. 309-32. https://doi.org/10.1002/9781118939314.ch12

[17] Pandey S, Goswami GK, Okoro HK, Fosso-Kankeu E Carbon Nanotubes in the 21st Century: An Advancement in Real Time Monitoring and Control of Environmental Water., Nano and Bio-Based Technologies for Wastewater Treatment (Chapter.8) 2019, 1, 265-301. ISBN: 9781119577119 https://doi.org/10.1002/9781119577119.ch8

[18] Fosso-Kankeu E, Kumar N, Pandey S, Ray S, Synthesis Of MoS2-Based Nanohybrid For Effective Removal Of Mercury From Aqueous Solution. Mine Water - Technological and Ecological Challenges; In: Khayrulina, E.; Wolkersdorfer, Ch.; Polyakova, S.; Bogush, A. Perm, Russia (Perm State University).ISBN 978-5-91252-145-42019, 175-184

[19] Pandey S, Kang M, 2LN-7: Modified biopolymer-locust bean gum based crosslinked hydrogels: Application in adsorption of cationic dye from aqueous solution, The Korean Society of Industrial and Engineering Chemistry, 2019, 155

[20]. Shi, Y, Xue Z, Wang X, Wang A.Q, Removal of methylene blue from aqueous solution by sorption on lignocellulose-g-poly (acrylic acid)/montmorillonite three-dimensional cross-linked polymeric network hydrogels. Polymer Bulletin.2013, 70,1163-1179. https://doi.org/10.1007/s00289-012-0898-4.

[21]. Pandey S. A Study on the Synthesis and Applications of Sol Gel Derived Composites of Polysaccharides and Silica Shodhganga@INFLIBNET http://hdl.handle.net/10603/234459

[22]. Sun, X. Liu, B. Jing, Z. Wang, H, Preparation and adsorption property of xylan/poly(acrylic acid) magnetic nanocomposite hydrogel adsorbent. Carbohydrate Polymers.2015, 118, 16-23. https://doi.org/10.1016/j.carbpol.2014.11.013

[23]. X. Wang, Z. Liu, X. Ye, K. Hu, H. Zhong, J. Yu, M. Jin, Z. Guo. A facile one-step approach to functionalized graphene oxide-based hydrogels used as effective adsorbents toward anionic dyes. Applied Surface Science, 308 (2014) 82-90. https://doi.org/10.1016/j.apsusc.2014.04.103

[24]. Luc ic M, Milosavljevic N, Radetic M, Šaponjic Z, Radoic `ic M, Krušic M.K. The potential application of $\mathrm{TiO} /$ /hydrogel nanocomposite for removal of various textile azo dyes. Separation and Purification Technology. 2014, 206-216. https://doi.org/10.1016/j.seppur.2013.11.002

[25]. Singh, V. Pandey, S. Singh, S.K. Sanghi, V. Removal of cadmium from aqueous solutions by adsorption using poly(acrylamide) modified guar gum-silica nanocomposites.Separation and Purification Technology. 2009, 67, 251-261. https://doi.org/10.1016/j.seppur.2009.02.023

[26]. Singh, V. Pandey, S. Singh, S.K..Sanghi, R. Sol-gel polycondensation of tetraethoxysilane in ethanol in presence of vinyl modified guar gum: synthesis of novel adsorbent materials.Journal Sol-gel Science and Technology. 2008, 47, 58-67. https://doi.org/10.1007/s10971-008-1715-2

[27]. Ghorai, S. Sinhamahpatra, A. Sarkar, A. Panda, A.B. Pal, S. Novel biodegradable nanocomposite based on XG-g-PAM/SiO2: Application of an efficient adsorbent for $\mathrm{Pb} 2+$ ions from aqueous solution. Bioresource Technology. 2012, 119, 181-190. https://doi.org/10.1016/j.biortech.2012.05.063

[28]. Pourjavadi, A.Tehrani, Z. M. Salimi, H. Banazadeh, A. Abedini, N hydrogel nanocomposite based on chitosan-g-acrylic acid and modified nanosilica with high adsorption capacity for heavy metal ion removal. Iran Polymer Journal. 2015, 24, 725-734.

https://doi.org/10.1007/s13726-015-0360-1

[29]. Ibrahim, A.G. Hai, F.A. Wahab, H.A Mahmoud, H. Synthesis, Characterization, Swelling Studies and Dye Removal of Chemically Crosslinked Acrylic Acid/Acrylamide/N,N-Dimethyl Acrylamide Hydrogels. American Journal of Applied Chemistry. 2016, 4, 221-234. https://doi.org/10.11648/j.ajac.20160406.12

[30]. Pandey, S. Mishra, S.B. Graft copolymerization of ethyl acrylate onto xanthan gum, using potassium peroxydisulphate as an initiator. International Journal of Biological Macromolecules. 2011, 49, 527-535. https://doi.org/10.1016/j.ijbiomac.2011.06.005

[31]. Makhado, E. Pandey, S. Nomngongo, P. Ramontja, J, Xanthan gum-clpoly(acrylic acid) / Reduced Graphene Oxide Hydrogel Nanocomposite as Adsorbent for Dye Removal. 9th Int'l Conf. on Advances in Science, Engineering,Technology \& Waste Management (ASETWM-17., pg192197, 2017.

[32]. Makhado, E. Pandey, S. Nomngongo, P. Ramontja, J, Preparation and characterization of xanthan gum-cl-poly(acrylic acid)/o-MWCNTs hydrogel nanocomposite as highly effective re-usable adsorbent for of methylene blue from aqueous solutions. Journal of Colloid and Interface Science, 2018, 513,700-714. https://doi.org/10.1016/j.jcis.2017.11.060

[33]. Lagergren S, About the theory of so-called adsorption of soluble substances." Svenska Vetenskapsakademiens Handlingar 1898, 24,1-39.

[34]. Ho, S.Y, McKay, G, Sorption of dye from aqueous solution by peat. Chemical Engineering Journal. 1998,70,115-124. https://doi.org/10.1016/S0923-0467(98)00076-1

[35]. Langmuir I, The adsorption of gases on plane surfaces of glass, mica and platinum. Journal of the American Chemical Society.1918,40,13611403. https://doi.org/10.1021/ja02242a004

[36]. Freundlich H.M.F, Uber die adsorption in losungen.\| International Journal of Research in Physical Chemistry \& Chemical Physics. 1906, $57,385-470$ https://doi.org/10.1515/zpch-1907-5723

[37]. Makhado, E. Pandey, S. Ramontja, J, Microwave-assisted green synthesis of xanthan gum grafted diethylamino ethyl methacrylate: an efficient adsorption of hexavalent chromium, Carbohydr. Polym., 2019, 222, 114989. https://doi.org/10.1016/j.carbpol.2019.114989

[38]. Elvis Fosso-Kankeu. 2019. Nano and Bio-based Technologies for wastewater treatment: Prediction and Control Tools for the dispersion of Pollutants in the Environment. Wiley Scrivener. ISBN: 978-1-11957709-6. Pp 301-336.

[39]. Elvis Fosso-Kankeu. 2019. New Horizons in Wastewaters Management: Emerging Monitoring and Remediation Strategies. Nova Science Publishers. ISBN: 978-1-53615-659-1.

[40]. Fosso-Kankeu E., Potgieter J. and Waanders F.B. 2019. Removal of malachite green and toluidine blue dyes from aqueous solution using a clay-biochar composite of bentonite and sweet sorghum bagasse. International Journal of Applied Engineering Research. 14(6): 13241333

[41]. N Kumar, E Fosso-Kankeu, SS Ray. 2019. Achieving controllable MoS2 nanostructures with increased interlayer spacing for efficient removal of $\mathrm{Pb}$ (II) from aquatic systems. ACS Applied Materials and Interfaces. 11: 19141-19155. https://doi.org/10.1021/acsami.9b03853

[42]. E Fosso-Kankeu, R Weideman, D Moyakhe, FB Waanders, M Le Roux, QP Campbell. 2019. Hydrothermal preparation of biochar from spent coffee grounds, and its application for the removal of cadmium from coal tailings leachate. The Journal of the Southern African Institute of Mining and Metallurgy. 119: 607-612. https://doi.org/10.17159/2411-9717/449/2019

[43]. R Gusain, N Kumar, E Fosso-Kankeu, SS Ray. 2019. Efficient removal of $\mathrm{Pb}$ (II) and $\mathrm{Cd}$ (II) from industrial mine water by a hierarchical MoS2/SH-MWCNT nanocomposite. ACS Omega. 4: 13922-13935. https://doi.org/10.1021/acsomega.9b01603

[44]. E. Fosso-Kankeu, A.F. Mulaba-Bafubiandi, B.B. Mamba and T.G. Barnard, Prediction of metal-adsorption behaviour in the remediation of water contamination using indigenous microorganisms. Journal of Environmental Management. Vol. 92, no. 10, pp. 2786-2793, 2011. https://doi.org/10.1016/j.jenvman.2011.06.025

[45]. H. Mittal, E. Fosso-Kankeu, Shivani B. Mishra, Ajay K. Mishra, Biosorption potential of Gum ghatti-g-poly (acrylic acid) and 
susceptibility to biodegradation by B. subtilis. International Journal of Biological Macromolecules. Vol. 62, pp. 370-378, 2013.

https://doi.org/10.1016/j.ijbiomac.2013.09.023

[46]. E. Fosso-Kankeu, H. Mittal, S.B. Mishra, A.K. Mishra, Gum ghatti and acrylic acid based biodegradable hydrogels for the effective adsorption of cationic dyes. Journal of Industrial and Engineering Chemistry. Vol. 22, pp. 171-178, 2015. https://doi.org/10.1016/j.jiec.2014.07.007

[47]. E. Fosso-Kankeu, H. Mittal, F. Waanders, I.O. Ntwampe, S.S. Ray, Preparation and characterization of gum karaya hydrogel nanocomposite flocculant for metal ions removal from mine effluents. International Journal of Environmental Science and Technology. Vol. 13, pp. 711724, 2016. https://doi.org/10.1007/s13762-015-0915-x

[48]. E. Fosso-Kankeu, F. Waanders, E. Maloy, Copolymerization of ethyl acrylate onto guar gum for the adsorption of $\mathrm{Mg}(\mathrm{II})$ and $\mathrm{Ca}(\mathrm{II})$ ions. Desalination and Water Treatment. doi: 10.1080/19443994.2016.1165147: pp. 1-10, 2016.

[49]. E. Fosso-Kankeu, F. Waanders, C.L. Fourie, Adsorption of Congo Red by surfactant-impregnated bentonite clay. Desalination and Water Treatment. doi: 10.1080/19443994.2016.1177599: pp. 1-9, 2016.

[50]. E. Fosso-Kankeu, H. Mittal, F. Waanders, S.S. Ray, Thermodynamic properties and adsorption behaviour of hydrogel nanocomposites for cadmium removal from mine effluents. Journal of Industrial and Engineering Chemistry. Vol. 48, pp. 151-161, 2017. https://doi.org/10.1016/j.jiec.2016.12.033

[51]. E. Fosso-Kankeu, F.B. Waanders, F.W. Steyn, Removal of $\mathrm{Cr}(\mathrm{VI})$ and $\mathrm{Zn}$ (II) from an aqueous solution using an organic-inorganic composite of bentonite-biochar-hematite. Desalination and Water Treatment. Vol. 59, pp. 144-153, 2017. https://doi.org/10.5004/dwt.2017.0059

[52]. L.P. Simelane, E. Fosso-Kankeu, P. Njobeh, S. Pandey, Response of bacterial biosorbents to chemical treatment as influenced by cell membrane structure and impact on the adsorption behaviour of dyes. Current Science. Vol. 114, no. 4, pp. 826-834, 2018. https://doi.org/10.18520/cs/v114/i04/826-834

[53]. E. Fosso-Kankeu, 2018. Synthesized af-PFCl and GG-g-P(AN)/TEOS hydrogel composite used in hybridized technique applied for AMD treatment. Journal of Physics and Chemistry of the Earth. 2018. https://doi.org/10.1016/j.pce.2018.02.015

[54]. A. Leudjo Taka, E. Fosso-Kankeu, K. Pillay, X. Yangkou Mbianda, Removal of cobalt and lead ions from wastewater samples using an insoluble nanosponge biopolymer composite: Adsorption isotherms, kinetics, thermodynamics and regeneration studies. Environmental Science and Pollution Research. 2018. 